\title{
Antenatal Dexamethasone Prior to Term Elective Caesarean Section and Incidence of Neonatal Respiratory Morbidity: A Randomized Trial
}

\author{
Magdy R. Ahmed \\ Department of Obstetrics and Gynecology, Faculty of Medicine, Suez Canal University
}

\begin{abstract}
Background: Elective caesarean section is a risk factor for the development of neonatal respiratory complications, resulted in increased admission to neonatal special care units. Aim: To assess the effect of prophylactic corticosteroids administration before elective CS at term in reducing neonatal respiratory morbidity and admission to neonatal special care units. Subjects and Methods: This randomized trial has been conducted among women subjected to term elective CS at Obstetrics and Gynecology Department of Suez Canal University Hospitals. Women who were eligible for the study ( $n=226$ ) were divided into two groups (study group and control group). At 37 weeks gestation, they received two intramuscular doses of $12 \mathrm{mg}$ dexamethasone, while the control group given the usual care without steroids. We examined adverse neonatal respiratory outcomes (Respiratory Distress Syndrome and Transient Tachypnea of the Newborn) and rates of neonatal care unit's admissions in both groups. Results: Neonates in the treatment group had a significantly lower overall incidence of respiratory distress morbidity $7.9 \%$ versus $23 \%$ in nontreated group mainly with TTN ( $7 \%$ versus $19.6 \%$ in non-treated group, p-value $=0.009^{*}$ ). Meanwhile; according to the degree of respiratory distress there was significantly lower incidence of both mild and moderate degrees of respiratory distress in the treatment group ( $7 \%$ and $0.9 \%$, respectively) to be (17\% and $5.3 \%$ respectively) in the control group. Conclusion: The effect of prophylactic corticosteroids administration before elective CS at term looks to be promising in reducing neonatal respiratory morbidity.
\end{abstract}

Keywords: Corticosteroids; RDS; TTN; Elective CS.

\section{Introduction}

Cesarean section can be considered an international phenomenon as rates have been increasing all over the world ${ }^{(1)}$. In Egypt; cesarean section rates have risen to 27.6 percent, which is above the World Health Organization recommendation, suggesting the possibility of inappropriate interventions at delivery ${ }^{(2)}$. It is well documented that performing cesarean deliveries prior to 39 weeks of gestation has been associated with many neonatal morbidities specially respiratory complications, mostly respiratory distress syndrome (RDS) and transient tachypnea of the newborn (TTN), with increasing rates of Neonatal Intensive Care Unit (NICU) admissions ${ }^{(3.4)}$. However, there is increased risk of respiratory morbidity within each gestational week from 37 to 39 weeks as this risk is decreasing with advancing in gestational age. Infants born between $37^{+0}$ and $37^{+6}$ weeks are at 1.7 times riskier than those born between $38^{+0}$ to $38^{+6}$ weeks; while this risk was 2.4 times in those infants born between $39^{+0}$ to $39^{+6}$ 
weeks ${ }^{(5)}$. Hence, many guidelines recommended that planned caesarean section should not be routinely carried out before 39 weeks of gestation ${ }^{(6-8)}$. Elective caesarean section per se is another risk factor for the development of neonatal respiratory complications in both term and preterm infants when compared to infants born vaginally ${ }^{(9)}$. This risk is mainly due to the inactivity of the sodium channels (on the apical side of the pulmonary epithelium which promotes alveolar fluid reabsorption to keep the air space dry throughout postnatal life) in those fetuses not exposed to the stress of normal labor with its resultant release of cortisol $^{(9)}$. Glucocorticoids appear to increase the number and function of these sodium channels, as well as, maturation of surfactant producing type II pneumocytes, providing a strong rationale for their exogenous administration in cases of elective caesarean deliveries ${ }^{(10)}$. No trials have been conducted for antenatal corticosteroids in mothers delivered by elective caesarean section at term. This has inspired us to assess the effect of prophylactic corticosteroid administration before elective caesarean section at term in reducing neonatal respiratory morbidity and admission rates to special care units with respiratory complications.

\section{Subjects and Methods}

This randomized trial has been conducted among women subjected to term elective CS at Obstetrics and Gynecology department, Suez Canal University Hospitals. Inclusion criteria included all elective CS that can be performed at 37 weeks gestation or beyond. Time of termination was, according to absolute obstetric indications (term rupture of membranes, onset of labor pains, non-reassuring CTG with or without sonographic features such as Doppler studies or BPP and bad obstetric history,... etc.) or social reasons such as maternal request. Women who had multiple gestations or a fetus with a major congenital anomaly and those with other medical or obstetrical conditions that would warrant early or immediate delivery and/or women who had received prophylactic dexamethasone during the current pregnancy were excluded from the study. Women eligible for the study $(n=226)$ were divided into two groups by simple randomization (study group and control group). They were also divided into subgroups according to the gestational age at termination $\left(37^{+0}-37^{+6}\right.$ to $\left.39^{+0}-39^{+6}\right)$. The study group received an explanation for the study and signed a consent form. At 37 weeks gestation, they received two intramuscular doses of $12 \mathrm{mg}$ dexamethasone (Dexamethasone ${ }^{\circledR}$, Sigma CO., Egypt) separated by 12 hours while the control group was given the usual care without steroids.

Caesarian deliveries were performed in the usual manner under spinal anesthesia, which is a protocol in our hospital as well as to eliminate the possible depressive effect of general anesthesia on the newborn. We examined the adverse neonatal respiratory outcomes such as RDS, and TTN in addition to the rates of NICU admissions in both groups. The attending pediatrician, who was blind to neonates in either group, was responsible for assessment of all neonates. Respiratory distress was diagnosed in the presence of required signs of respiratory distress (cyanosis, grunting, inspiratory stridor, nasal flaring and tachypnea). There may also be retractions in the intercostal, subcostal, or supracostal spaces with specific radiological features ${ }^{(11)}$. Transient tachypnea of the newborn was also diagnosed by the attending pediatrician by tachypnea immediately after birth or within two hours, with another predictable sign of respiratory distress ${ }^{(11)}$. To the NICU admitted cases, respiratory distress was graded 
according to oximetry measurements as mild if the baby received less than $30 \%$ oxygen, severe if it received more than $70 \%$ oxygen or ventilatory support, otherwise moderate ${ }^{(12)}$. The chest $\mathrm{x}$ - ray for NICU admitted cases assessed the radiological features of transient tachypnea of the newborn as diffuse parenchymal infiltrate or intralobar fluid accumulation while respiratory distress syndrome as reticular granular pattern ${ }^{(13)}$.

\section{Statistical Analysis}

The data were processed using SPSS version 15 (SPSS Inc., Chicago, IL, USA). Quantities data were expressed as means \pm SD and qualitative data were expressed as numbers and percentages. Analysis of variance test was used to test the significance of difference for quantitative variables while Chi-square was used to test significance for qualitative variables. Adjusted odds ratios (OR) for the association between maternal outcomes and delivery time derived from logistic regression models were calculated. A two sided $p$-value $<0.05$ was considered statistically significant.

\section{Results}

Baseline maternal and neonatal characteristics at cesarean delivery in both groups were shown in (Table 1). There was no statistically significant difference between both groups regarding maternal age, BMI at presentation, neonatal sex, birth weight, and gestational age at delivery. Previous CS was the commonest indication for elective cesarean delivery in both groups $(44.7 \%$ in the treatment group and $41.9 \%$ in the control group).

Table 1: Baseline characteristics between all studied groups

\begin{tabular}{|c|c|c|c|c|c|}
\hline & \multicolumn{2}{|c|}{$\begin{array}{l}\text { Treatment group } \\
\qquad(\mathrm{n}=114)\end{array}$} & \multicolumn{2}{|c|}{$\begin{array}{l}\text { Control group } \\
(n=112)\end{array}$} & P-value \\
\hline Maternal Age (Mean \pm SD) & \multicolumn{2}{|c|}{$27.5 \pm 9.7$} & \multicolumn{2}{|c|}{$28.2 \pm 8.3$} & 0.2 \\
\hline $\begin{array}{l}\text { Maternal BMI at presentation } \\
\text { (Median range) }\end{array}$ & \multicolumn{2}{|c|}{$31.1(26.9-52.3)$} & \multicolumn{2}{|c|}{$30.6(25.1-51.1)$} & 0.4 \\
\hline $\begin{array}{l}\text { Neonatal sex } \\
-\quad \text { Male } \\
-\quad \text { Female } \\
\end{array}$ & $\begin{array}{l}49 \\
65 \\
\end{array}$ & $\begin{array}{l}42.9 \% \\
57.1 \% \\
\end{array}$ & $\begin{array}{l}54 \\
58\end{array}$ & $\begin{array}{l}48.2 \% \\
51.8 \% \\
\end{array}$ & 0.5 \\
\hline $\begin{array}{l}\text { Birth weight } \\
-<2.5 \mathrm{Kg} \\
-\geq 2.5 \mathrm{Kg} \\
- \text { Mean } \pm \text { SD }\end{array}$ & $\begin{array}{r}3 \\
111 \\
3\end{array}$ & $\begin{array}{l}2.6 \% \\
97.4 \% \\
.8\end{array}$ & $\begin{array}{c}4 \\
108 \\
\vdots\end{array}$ & $\begin{array}{l}3.6 \% \\
96.4 \% \\
0.7\end{array}$ & 0.7 \\
\hline $\begin{array}{l}\text { Gestational age at delivery } \\
-\quad 37-37^{+6} \\
-\quad 38-38^{+6} \\
-\quad 39-39^{+6}\end{array}$ & $\begin{array}{l}20 \\
37 \\
57\end{array}$ & $\begin{array}{c}17.5 \% \\
32.5 \% \\
50 \%\end{array}$ & $\begin{array}{l}18 \\
38 \\
56\end{array}$ & $\begin{array}{c}16.1 \% \\
33 \cdot 9 \% \\
50 \%\end{array}$ & $\begin{array}{l}0.9 \\
0.9 \\
0.8\end{array}$ \\
\hline $\begin{array}{l}\text { Indications for CS } \\
\text { - Previous CS } \\
\text { - Previous hysterotomy/myomectomy } \\
\text { - Malpresentations } \\
\text { - Maternal request } \\
\text { - Others }\end{array}$ & $\begin{array}{l}51 \\
21 \\
31 \\
7 \\
4\end{array}$ & $\begin{array}{c}44.7 \% \\
18.4 \% \\
27.2 \% \\
6.2 \% \\
3.5 \%\end{array}$ & $\begin{array}{c}47 \\
20 \\
33 \\
8 \\
4\end{array}$ & $\begin{array}{c}41.9 \% \\
17.9 \% \\
29.5 \% \\
7.1 \% \\
3.6 \%\end{array}$ & $\begin{array}{l}0.7 \\
0.9 \\
0.8 \\
0.9 \\
0.7\end{array}$ \\
\hline
\end{tabular}

Statistically significant at p-value $\leq 0.05$ 

Neonates of women treated with dexamethasone had a significantly lower overall incidence of respiratory distress morbidity $(7.9 \%$ versus $23.2 \%$ in non-treated group) mainly in the form of TTN ( $7 \%$ versus $19.6 \%$ in non-treated group, $p=0.009$ ). In addition, according to the degree of respiratory distress there was significantly lower incidence of both mild and moderate degrees of respiratory distress in the treatment group ( $7 \%$ and $0.9 \%$, respectively) compared to the control group ( $17 \%$ and $5.3 \%$ respectively). Although, no neonatal mortality reported in both groups; only one neonate in the treatment group was admitted to the NICU (0.9\%) while seven neonates of the control group had been admitted to NICU (6.3\%). Admission in neonatal special care units was found to be longer in the control group (3.8 days) in comparison to the treatment group (1.1 days) with also a statistically significant difference $(p=0.001)$ (Table 2$)$.

Table 2: Study outcomes between both groups

\begin{tabular}{|l|cccc|}
\hline & $\begin{array}{c}\text { Treatment } \\
\text { group } \\
(\mathrm{n}=114)\end{array}$ & $\begin{array}{c}\text { Control } \\
\text { group } \\
(\mathrm{n}=112)\end{array}$ & $\begin{array}{c}\mathrm{P}- \\
\text { value }\end{array}$ & $\begin{array}{c}\mathrm{RR} \\
(95 \% \mathrm{Cl})\end{array}$ \\
\hline Type of respiratory distress & $9(7.9 \%)$ & $26(23.2 \%)$ & $0.002^{*}$ & $0.3(0.2-0.7)$ \\
Respiratory distress syndrome & $1(0.9 \%)$ & $4(3.6 \%)$ & 0.4 & $0.3(0.02-2.2)$ \\
Transient tachypnea of newborn & $8(7.01 \%)$ & $22(19.6 \%)$ & $0.009^{*}$ & $0.4(0.2-0.7)$ \\
\hline Degree of respiratory distress & & & & \\
$\quad$ Mild & $8(7.01 \%)$ & $19(16.9 \%)$ & $0.03^{*}$ & $0.5(0.2-0.9)$ \\
$\quad$ Moderate & $1(0.9 \%)$ & $6(5.3 \%)$ & $0.01^{*}$ & $0.2(0.02-1.7)$ \\
Severe & 0 & $1(0.8 \%)$ & 0.5 & - \\
\hline Admission to NICU & $1(0.9 \%)$ & $7(6.3 \%)$ & 0.07 & $0.1(0.01-1.12)$ \\
Neonatal mortality & 0 & 0 & - & - \\
Time in special care unit (days) & $1.1 \pm 0.03$ & $3.8 \pm 0.09$ & $0.001^{*}$ & - \\
\hline
\end{tabular}

*=Statistically significant at $\mathrm{p}$-value $\leq 0.05 ; \mathrm{RR}$ : relative risk, $\mathrm{Cl}$ : confidence interval

Comparing the different subgroups of gestational ages in each of the study and control groups revealed that, in both groups, the incidence of neonatal respiratory morbidities decreases with increasing gestational age. At gestational age $37^{+0}-37^{+6}$ weeks, the treatment group had statistically significant lower incidence of TTN that wasn't noted for RDS, probably attributed to the relatively small sample size ( $25 \%$ \& $5 \%$, respectively) in comparison to the same gestational age in the control group ( $72.2 \% \& 16.7 \%$ respectively). With advanced gestational age, no significant difference had been reported which might be explained by a relatively small sample size in each subgroup. Regarding the degree of respiratory distress, it was noticed that all degrees of respiratory distress were found to be significantly higher in the control group at $37^{+0}-37^{+6}$ weeks when compared to the more advanced gestational ages of the same group with statistically significant difference. Of great importance, rate of NICU admission and stays in special care units were significantly higher in the control group at $37^{+0}$ $37^{+6}$ weeks ( $33.3 \%$ and 4 days respectively) in comparison to the same gestational age of the study group ( $5 \%$ and 1.4 days respectively) (Table 3 ). Risk assessment of the different neonatal morbidities by gestational age at the study group was compared to control group of the same gestational age. Interestingly, dexamethasone was significantly effective in re- 
ducing risk of different neonatal morbidities when given at gestational age $37^{+0}$ $37^{+6}$ weeks. At this gestational age, treatment with dexamethasone had re- duced the risk of RDS by 3 times, TTN by 2.5 times and admission to NICU by 5 times (Table 4).

Table 3: Outcomes between both groups according to gestational age at delivery

\begin{tabular}{|c|c|c|c|c|c|c|c|c|}
\hline \multirow[b]{2}{*}{-} & \multicolumn{4}{|c|}{ Treatment group $(n=114)$} & \multicolumn{3}{|c|}{ Control group $(n=112)$} & \multirow[b]{2}{*}{$\begin{array}{c}\mathrm{P}- \\
\text { value }\end{array}$} \\
\hline & $\begin{array}{l}37-37^{+6} \\
(\mathrm{~N}=20)\end{array}$ & $\begin{array}{c}38-38^{+6} \\
(\mathrm{~N}=37)\end{array}$ & $\begin{array}{l}39-39^{+6} \\
(\mathrm{~N}=57)\end{array}$ & P-value & $\begin{array}{l}37-37^{+6} \\
(N=18)\end{array}$ & $\begin{array}{l}38-38^{+6} \\
(\mathrm{~N}=38)\end{array}$ & $\begin{array}{l}39-39^{+6} \\
(N=56)\end{array}$ & \\
\hline $\begin{array}{l}\text { Type of RD } \\
\text { - RD syn- } \\
\text { drome } \\
\text { - TT of new- } \\
\text { born }\end{array}$ & $\begin{array}{c}1(5 \%) \\
5(25 \%)\end{array}$ & $\begin{array}{c}0 \\
2(5.4 \%)\end{array}$ & $\begin{array}{c}0 \\
1(1.8 \%)\end{array}$ & $\begin{array}{c}0.09 \\
0.002^{@}\end{array}$ & $\begin{array}{c}3(16.7 \%) \\
\left.13^{\#} 72.2 \%\right)\end{array}$ & $\begin{array}{c}1(2.6 \%) \\
7(18.4 \%)\end{array}$ & $\begin{array}{c}0 \\
2(3.6 \%)\end{array}$ & $\begin{array}{l}0.003^{@} \\
0.001^{@}\end{array}$ \\
\hline $\begin{array}{l}\text { Severity of RD } \\
\text { - Mild } \\
\text { - Moderate } \\
\text { - Severe }\end{array}$ & $\begin{array}{c}5(25 \%) \\
1(5 \%) \\
0\end{array}$ & $\begin{array}{c}2(5 \cdot 4 \%) \\
0 \\
0\end{array}$ & $\begin{array}{c}1(1.8 \%) \\
0 \\
0\end{array}$ & $\begin{array}{c}0.002^{@} \\
0.09 \\
-\end{array}$ & $\begin{array}{c}10(55.5 \%) \\
5(22.2 \%) \\
1(11.1 \%)\end{array}$ & $\begin{array}{c}7(18.4 \%) \\
1(2.6 \%) \\
0\end{array}$ & $\begin{array}{c}2(3.6 \%) \\
0 \\
0\end{array}$ & $\begin{array}{l}0.001^{@} \\
0.003^{@} \\
0.004^{@}\end{array}$ \\
\hline $\begin{array}{l}\text { Admission to } \\
\text { NICU }\end{array}$ & $1(5 \%)$ & 0 & 0 & 0.09 & $6(33.3 \%)^{\#}$ & $1(2.6 \%)$ & 0 & $0.001^{@}$ \\
\hline $\begin{array}{l}\text { Time in special } \\
\text { care unit } \\
\text { (days) }\end{array}$ & $1.4 \pm 0.08$ & $0.8 \pm 0.06$ & - & $0.001^{@}$ & $4 \pm 0.02^{\#}$ & $1.6 \pm 0.07$ & - & $0.001^{@}$ \\
\hline $\begin{array}{l}\text { Neonatal } \\
\text { mortality }\end{array}$ & 0 & 0 & 0 & - & 0 & 0 & 0 & - \\
\hline
\end{tabular}

$\mathrm{RD}=$ respiratory distress; $\mathrm{TT}=$ Transient tachypnea; ${ }^{\circledR}=$ Statistically significant difference between different gestational ages at same group; \# Statistically significant difference versus same gestational age at other group.

\section{Discussion}

As far as we know, this is the first randomized trial to assess the effect corticosteroids (Dexamethasone) administration before elective caesarean section at term in reducing neonatal respiratory morbidity. Until now, there has been a lack of evidence about the prophylactic role of corticosteroid administration given at term pregnancy to improve neonatal respiratory outcomes. In the current study, we evaluated the effect of dexamethasone administration before elective caesarean section at term in reducing neonatal respiratory morbidities either RDS or TTN at various gestational ages ranged from $37^{+0}-37^{+6}$ to $39^{+0}-39^{+6}$ weeks in the study group compared to control group. Dexa methasone was given before elective caesarean section at term; it was found to reduce respiratory distress morbidity mainly TTN and admission to a special care baby unit. In our study, the rate of such admission was $6.3 \%$ in the control group while it was $0.9 \%$ in the treatment group, in addition to lower overall incidence of respiratory distress morbidity $7.9 \%$ in study group vs. $23 \%$ in non-treated group mainly with transient tachypnea of newborn ( $7 \%$ in study group versus $19.6 \%$ in non-treated group). Glucocorticoids appear to increase the number and function of sodium channels, which located on the apical side of the pulmonary epithelium, which allows reabsorption of liquid from the lung to keep the air space dry throughout postnatal life, hence allowing the lung to switch from fluid secretion to fluid absorption eliminating the risk of $\operatorname{TTN}^{(14)}$. 
Table 4: Risk of different neonatal morbidities by gestational age at study group (reference group: control group of same gestational age)

\begin{tabular}{|l|lcc|}
\hline Morbidity & Treated Group & RR & $95 \% \mathrm{Cl}$ \\
\hline \multirow{3}{*}{ Respiratory Distress syndrome } & $37-37^{+6}$ & 0.3 & $0.03-2.6$ \\
& $38-38^{+6}$ & - & - \\
& $39-39^{+6}$ & - & - \\
\hline \multirow{3}{*}{ Transient Tachypnea of newborn } & $37-37^{+6}$ & 0.4 & $0.2-0.8$ \\
& $38-38^{+6}$ & 0.2 & $0.06-1.3$ \\
& $39-39^{+6}$ & 0.5 & $0.04-5.3$ \\
\hline \multirow{3}{*}{ Admission to NICU } & $37-37^{+6}$ & 0.2 & $0.01-1.1$ \\
& $38-38^{+6}$ & - & - \\
& $39-39^{+6}$ & - & - \\
\hline
\end{tabular}

$\mathrm{RR}$ : relative risk, $\mathrm{Cl}$ : confidence interval

Without another source of corticosteroids, elective caesarean section will disrupt this process $^{(12)}$. The view that $\mathrm{Na}+$ transport plays a vital role in respiratory adaptation at birth is supported by the finding of transient tachypnea of the newborn or other respiratory failure in babies in which the pump has not been activated or genetically abnormal ${ }^{(15)}$. Similar to our results, Stutchfield et $\mathrm{al}^{(12)}$, in their multicenteric pragmatic randomized trial comparing prophylactic antenatal corticosteroid (betamethasone) administration with placebo or with no treatment, given before elective caesarean section at term (at or after 37 weeks of gestation) and found that the incidence of admission with respiratory distress was $5.1 \%$ in the control group and $2.4 \%$ in the treatment group. The incidence of TTN was $4 \%$ in the control group and $2.1 \%$ in the treatment group while the incidence of respiratory distress syndrome was $1.1 \%$ in the control group and $0.2 \%$ in the treatment group. It was noticed that as gestational age increases, the incidence of respiratory distress morbidity mainly TTN or the degree of its severity dramatically decreases; it was noticed that all degrees of respiratory distress were found to be significantly higher in the control group at $37^{+0}-37^{+6}$ weeks when compared to the more advanced gestational ages of the same group with statistically significant difference. Comparing the study and control group at $37^{+0}-37^{+6}$ weeks gestation, the situation is completely different as the treatment group had significantly lower incidence of TTN only in comparison to the same gestational age in the control group which reflect the beneficial effect of dexamethasone administration at term pregnancy prior to an elective cesarean delivery. The timetable with which lung liquid volume and secretion decline before term delivery underlines the importance of the last few days of gestation in adapting the fetus for the postnatal life. In addition, $\mathrm{Na}+$ channels increase in number and function with the approach of delivery ${ }^{(16)}$. Maturation of this mechanism appears to be under the control of cortisol and thyroid hormone, both of which increase also over the last few days of gestation $^{(10)}$. Hence, several studies indicated that neonatal outcomes are improved by delaying cesarean until 39 weeks of gestation, the American College of Obstetricians and Gynecologists as well, recommended delaying cesarean delivery until 39 weeks of gestation in the absence of obstetric or medical indications for early delivery to nullify neonatal respiratory morbidities. In brief, delaying 
elective Caesarian Section until 39 weeks and the prophylactic administration of antenatal dexamethasone at term both can reduce neonatal respiratory morbidity and admissions to special care baby units.

\section{Conclusion}

The effect of prophylactic corticosteroid administration before elective caesarean section at term looks to be promising in reducing neonatal respiratory morbidity and admission rates to special care units with respiratory complications. Future studies on larger groups of patients are recommended.

\section{Conflicts of interest}

The author reports no conflict of interest or financial support.

\section{References}

1. Villar J, Carroli G, Zavaleta N, et al. Maternal and neonatal individual risks and benefits associated with caesarean delivery: multicentre prospective study. BMJ 2007; 17;335 (7628): 1025. Epub 2007 Oct 30.

2. El-Zanaty F and Way AA. Egypt Demographic and Health Survey. Cairo, Egypt: Ministry of Health and Population [Arab Republic of Egypt], National Population Council [Arab Republic of Egypt]. 2009.

3. Berg VA, van Elburg RM, van Geijn HP, Fetter WP. Neonatal respiratory morbidity following elective caesarean section in term infants. A 5-year retrospective study and a review of the literature. Eur J Obstet Gynecol Reprod Biol 2001, 98(1):9-13.

4. Zanardo V, Simbi KA, Vedovato S, Trevisanuto $D$. The influence of timing of elective cesarean section on neonatal resuscitation risk. Pediatr Crit Care Med 2004, 5 (6):566-570.

5. Morrison JJ, Rennie JM, Milton PJ. Neonatal respiratory morbidity and mode of delivery at term: influence of timing of elective caesarean section. BJOG 1995;102:1016.
6. Clark SL, Miller DD, Belfort MA, Dildy GA, Frye DK, Meyers JA. Neonatal and maternal outcomes associated with elective term delivery. Am J Obstet Gynecol 2009, 200 (2): e151-154, 156.

7. Yee W, Amin H, Wood S. Elective cesarean delivery, neonatal intensive care unit admission, and neonatal respiratory distress. J Obstet Gynecol 2008, 111 (4): 823-828.

8. Zanardo V, Padovani E, Pittini C, Doglioni $\mathrm{N}$, Ferrante A, Trevisanuto D. The influence of timing of elective cesarean section on risk of neonatal pneumothorax. J Pediatr 2007, 150 (3): 252-255.

9. Wallace, MJ., Hooper, SB., \& Harding, R. Role of the adrenal glands in the maturation of lung liquid secretory mechanisms in fetal sheep. Am J Phys 1996;270 (2) 33-40.

10. Jain L and Dudell GG. Respiratory transition in infants delivered by cesarean section. Seminars in Perinatology 2006; 30:296-304.

11. Cloherty J, Stark A, Eichenwald E. Manual of Neonatal Care. 6th Ed. Lippincott, Wilkins and Williams; 2008.

12. Stutchfield P, Whitaker R, Russell I et al. Antenatal Steroids for Term Elective Caesarean Section (ASTECS) Research Team. Antenatal betamethasone and incidence of neonatal respiratory distress after elective caesarean section: pragmatic randomized trial. BMJ 2005;331 (7518): 662.

13. Kurl $\mathrm{S}$, Heinonen KM, Kiekara $\mathrm{O}$. The first chest radiograph in neonates exhibiting respiratory distress at birth. Clin Pediatr (Phila) 1997:285-9.

14. O'Brodovich HM. Immature epithelial $\mathrm{Na}+$ channel expression is one of the pathogenic mechanisms leading to human neonatal respiratory distress syndrome. Proc Assoc Am Physicians1996 (108): 345-55.

15. Gowen CW , Lawson EE, Gingras J, Boucher RC, Gatzy JT, Knowles MR : Electrical potential difference and ion transport across nasal epithelium of term neonates: correlation with mode of delivery, transient tachypnea of the newborn, and respiratory rate. J. ped.1998: 113, (1) pp. 121-127

16. Baines, DL., Folkesson, HG., Norlin, A., Bingle, CD., Yuan, HT., Olver, RE. The influence of mode of delivery, hormonal status 
and postnatal $\mathrm{O}_{2}$ environment on epithelial sodium channel expression in perinatal guinea-pig lung. Phys J. 2000;522, (1)147157, ISSN 1469-7793. 
Running title: Steroids Prior to Term Elective Caesarean Section. 